PREMIO DE ARTÍCULOS JURÍDICOS «GARCÍA GOYENA» DECIMOQUINTA CONVOCATORIA (CURSO 2015-2016) FACULTAD DE DERECHO. UNIVERSIDAD NACIONAL DE EDUCACIÓN A DISTANCIA 

REVISTA DE DERECHO UNED, NÚM. 18, 2016

\title{
PRIMER PREMIO
}

\author{
SHARI'A RISK: ALGUNAS REFLEXIONES \\ A PROPÓSITO DE LOS RIESGOS ASOCIADOS \\ A LA JUDICIALIZACIÓN DE CONTRATOS \\ DE FINANCIACIÓN ISLÁMICOS \\ BAJO EL REGLAMENTO ROMA I
}

\section{SHARI'A RISK: ON THE RISKS RELATED TO ISLAMIC FINANCE LITIGATION IN SECULAR COURTS UNDER THE ROME I REGULATION}

BRuno Martín BaUmeister

Resumen: El peso demográfico de la población musulmana en el mundo, unido al crecimiento económico de algunos países del Golfo Pérsico, han contribuido a que el derecho financiero islámico represente, en la actualidad, una práctica jurídica cada vez más implantada en países de África, Oriente Medio, Sudeste Asiático y -en menor medida- Europa y Norteamérica. En este trabajo nos proponemos delimitar la naturaleza del derecho financiero islámico y examinar las dificultades que se derivan de la sumisión a la sharía de un contrato de financiación así como de la determinación de la ley aplicable en defecto de pacto de sumisión válido conforme al Reglamento Roma I, prestando especial atención al esquema de financiación denominado murabaha. Finalmente, nos proponemos demostrar que el auge de las finanzas islámicas, tal y como se entienden en la actualidad, ha terminado por generar -paradójicamente- un fenómeno de huida del derecho financiero islámico, de modo que éste sea percibido cada vez menos como «ley aplicable» y más como «riesgo» del contrato. 
Abstract: The worldwide growth of Muslim population and GCC's booming economies have turned Islamic finance into an ever more popular practice area in jurisdictions of Africa, the Middle East, Southeast Asia and -to a lesser extent- Europe and North America. This paper describes the nature of Islamic law as applied to financing transactions, in particular, the complexities deriving from Shari'a as choice of law and Shari'a as a legal system capable of being chosen under closest connection principles under Rome I Regulation. Special attention will be paid to a financing scheme named murabaha. Finally, this paper shows how the global success of Islamic finance has made Islamic law -paradoxically- less attractive under choice of law considerations, so that it is no longer perceived as «law» but as «risk».

Palabras clave: sharía; murabaha; Shari'a risk; ley aplicable; Roma I.

Keywords: Shari'a; murabahah; Shari'a risk; choice of law; Rome I.

Recepción original: 9/11/2015

Aceptación original: 15/03/2016

Sumario: I. Introducción. II. Delimitación de la naturaleza del derecho financiero islámico. III. Esquemas de financiación islámicos. IV. El derecho islámico como ley aplicable. V. Ley aplicable a falta de elección. VI. Conclusiones.

\section{INTRODUCCIÓN}

La industria financiera islámica ha experimentado un crecimiento notable en las últimas décadas, impulsada por la creciente acumulación de riqueza de los países islámicos exportadores de petróleo y por el fuerte aumento de la población musulmana, dentro y fuera del mundo islámico, que busca oportunidades y productos de inversión acordes con sus creencias religiosas ${ }^{1}$. En los últimos treinta años la

${ }^{1}$ Aunque las finanzas islámicas son tan antiguas como el Islam, la industria financiera islámica moderna nace en Malasia en los años 50 del s. XX y empieza a generalizarse en Egipto a partir del año 1963 con la creación de la primera cooperativa de microcréditos denominada Mit Ghamr. En sus inicios, la actividad financiera islámica es muy básica debido, en parte, al subdesarrollo económico de la región, la utilización de modelos contractuales cerrados y arcaicos, la falta de expertos en la materia y la utilización exclusiva del árabe como lengua de contrato. La constitución en 1973 del Nasser Social Bank en Egipto representa la primera experiencia de banca comercial islámica a mayor escala. Entre los años 70 y 90 el derecho financiero islámico atraviesa profundos cambios relacionados con el desarrollo económico derivado de la exportación de petróleo en las monarquías del Golfo Pérsico, el Panislamismo y una nueva sensibilidad hacia el Islam en el mundo de los negocios. En este periodo surgen los primeros 
industria financiera islámica ha pasado de ser un nicho de mercado marginal a representar una práctica bancaria cada vez más implantada en países de África, Oriente Medio y Sudeste Asiático y que encuentra cada vez mayor aceptación entre inversores, bancos internacionales y despachos de abogados.

Aunque más adelante profundizaremos en su delimitación, el derecho financiero islámico (denominado en inglés Islamic Finance o Shari'a Compliant Finance) puede describirse como un cuerpo de principios de contratación bancaria -no siempre positivados en un ordenamiento jurídico estatal- coherente con los preceptos del Is$\mathrm{lam}^{2}$. El derecho financiero islámico ocupa, a día de hoy, un terreno híbrido en el que confluyen creencias religiosas basadas en la sharía y consideraciones convencionales de rentabilidad financiera. Este mestizaje de intereses obedece, de un lado, a una mayor sensibilidad al hecho religioso islámico en el mundo de los negocios y, de otro, a la preeminencia de la práctica bancaria convencional en todo el orbe islámico -incluso en aquellos países que más han adaptado su ordenamiento jurídico a la sharía-. Así, la incompatibilidad con la sharía de algunos esquemas convencionales de financiación -como sucede, por ejemplo, con los sistemas remuneratorios basados en un tipo de interés o con la utilización de instrumentos derivados que entrañan

grandes bancos islámicos, algunos -aunque pocos- bancos occidentales crean un área de financiación islámica, se constituyen las primeras agencias de expertos islámicos (Sharia boards), los documentos contractuales empiezan a redactarse también en inglés, se abandonan progresivamente los modelos contractuales cerrados y se crean la AAOIFI y la IFSB. La aprobación en 1998 de la Dow Jones Islamic Indexes Fatwa supone un revulsivo para los mercados de capitales islámicos, dado que por primera vez se admite la noción de «impureza tolerable» de ciertas operaciones financieras convencionales siempre que estén sujetas a mecanismos de «depuración» consistentes en donaciones de escasa entidad para fines caritativos. Hasta los años 90, las principales áreas de práctica se centran en el sector inmobiliario y el capital riesgo. Con el tiempo la actividad financiera islámica deviene cada vez más compleja tanto desde el punto de vista contractual como de cuestiones evaluables bajo la sharía. En los años 90 y principios de los 2000, los fondos de inversión acogidos a estructuras fiscales eficientes se convierten en el principal sector de negocio, especialmente los fondos de inversión inmobiliarios. La emisión de letras del tesoro en forma de sukuk acordada en 2002 por el gobierno de Malasia representa otro gran hito en el desarrollo de las finanzas islámicas. A partir de 2004 algunos grandes bancos internacionales como Citibank, HSBC, RBS, UBS, Goldman Sachs o Deutsche Bank crean o amplían sus prácticas de Islamic Finan$c e$, centradas principalmente en fondos de inversión, mercados de capitales y titulizaciones, si bien algunas operaciones son objeto de controversia por parte de los expertos islámicos. Véase GARCÎA HERRERO, A. / MORENO, C. / SOLÉ, J. (2008), «Finanzas Islámicas», Estabilidad Financiera, Banco de España, n. ${ }^{\circ}$ 15, pp. 121-141.

${ }^{2}$ El término "derecho financiero islámico» no está ausente de controversia. La mayoría de los autores convienen, sin embargo, que existen modalidades contractuales suficientemente perfiladas que permiten hablar de un «derecho financiero islámico» y no sólo de una concepción islámica de la financiación. 
un elemento de especulación-, exige que los operadores involucrados en esta práctica de mercado desarrollen nuevos esquemas que satisfagan tanto a los partícipes que precisan de una estructura de financiación compatible (compliant) con los preceptos del Islam como a aquellos partícipes cuya principal preocupación reside en que el proyecto sea sindicable (bankable) en los mercados financieros internacionales.

En este trabajo nos proponemos examinar los problemas que se derivan de la sumisión a la ley islámica de un contrato de financiación así como de la determinación de la ley aplicable en defecto de cláusula de sumisión válida bajo el Reglamento Roma I ${ }^{3}$. En la actualidad, se estima que aproximadamente el $80 \%$ de las operaciones financieras compatibles con la sharía se realizan bajo el esquema de financiación denominado murabaha ${ }^{4}$, por lo que nos detendremos en el estudio de esta figura y su problemática bajo el punto de vista de la ley aplicable.

\section{DELIMITACIÓN DE LA NATURALEZA DEL DERECHO FINANCIERO ISLÁMICO}

De acuerdo con la visión tradicional, el derecho financiero islámico sería un cuerpo de normas jurídico-privadas y, en particular, de contratación bancaria, coherente con los preceptos de la sharía 5 . Esta

\footnotetext{
${ }^{3}$ Nuestro análisis se ciñe a aquellas operaciones de financiación que guarden relación con, al menos, una parte contractual con «residencia habitual» en un Estado miembro de la Unión Europea.

${ }^{4}$ En la medida de lo posible, este trabajo trata de respetar las transcripciones del árabe al español propuestas en RILOBA, F. (1986), Gramática árabe-española, 3. a ed., EDI-6, S. A.

${ }^{5}$ Esta concepción forma parte de un fenómeno más amplio, que algunos autores denominan «economía islámica», y que puede definirse como una economía de mercado sujeta a los preceptos del Islam. Como es también habitual en los ordenamientos privados occidentales, en materia de contratación la sharía establece el principio de autonomía privada de la voluntad, de modo que se presume permitido (halal) todo lo que no esté expresamente prohibido (haram). A pesar de que la sharía recoge gran número de normas teóricamente aplicables al tráfico financiero, en la actualidad existe cierto consenso en que el derecho financiero islámico debe pivotar - una vez aplicado el «filtro de modernidad»-sobre cinco principios, tres negativos y dos positivos, extraídos de las cuatro escuelas jurídicas suníes. De acuerdo con la clasificación comúnmente aceptada, los tres principios negativos son la prohibición de riba (exceso o incremento), la prohibición de garar y maysir (incertidumbre y especulación) y la prohibición de invertir en determinados productos o actividades haram. Los dos principios positivos establecen la obligación de repartir pérdidas y ganancias entre las partes contractuales y la obligación de que todo negocio guarde relación con un activo subyacente tangible. La prohibición de riba está expresamente mencionada en varios pasajes del Corán y de la Sunna. La prohibición de riba constituye la clave de bóveda del derecho financiero islámico y es, quizá, el rasgo que más lo diferencia del derecho financiero convencional. En su acepción más amplia el término riba describe el valor añadido obtenido por
} 


\section{visión concibe el derecho financiero islámico como parte del derecho positivo de un determinado estado y su creación se enmarcaría den-}

una parte contractual sin contraprestación. En sentido estricto, comprende el exceso o incremento sobre el importe de un principal cifrado en dinero que se devenga por el mero transcurso del tiempo. De acuerdo con esta concepción y, a diferencia de la financiación convencional, en la que el prestamista obtiene un derecho al interés que es independiente de los resultados prósperos o adversos de la actividad financiada, el prestamista debe asumir el riesgo y ventura -las pérdidas y ganancias- del negocio en el que invierte sus fondos. Es importante señalar que para el derecho financiero islámico no existe una diferencia entre el préstamo usurario y el préstamo con interés. Ambos préstamos se encuentran en el ámbito de aplicación de la prohibición, siendo el primero simplemente un préstamo con un interés más elevado. No obstante, en los últimos años se ha venido imponiendo en la doctrina la idea de que la prohibición de riba debe ceñirse exclusivamente a la fijación de un interés fijo ( fa'ida). La importancia de la prohibición de riba no estriba tanto en su reconocimiento en los ordenamientos jurídicos seculares -que suele ser poco frecuente-, sino en su caracterización como principio religioso que informa los «códigos de buenas prácticas islámicas» aprobados por ciertas autoridades regulatorias. Finalmente, si bien riba no está necesariamente vinculado al dinero como activo subyacente, conviene destacar que el dinero carece, además, de valor intrínseco y cualesquiera ganancias generadas sobre el dinero están prohibidas por la sharía. Las prohibiciones de garar y de maysir están estrechamente vinculadas y se refieren a la incertidumbre y a la especulación, respectivamente. Los presupuestos objetivos de la prohibición de garar exigen que la incertidumbre tenga cierta relevancia o entidad, no bastando la incertidumbre sobre aspectos nimios o desdeñables; que se dé en negocios que conlleven prestaciones recíprocas; y que recaiga sobre un elemento esencial del negocio. De acuerdo con este principio, no son admisibles, por ejemplo, el seguro convencional y las opciones de compra y venta con beneficio desconocido. No obstante, la incertidumbre no debe confundirse con el riesgo de negocio, que sí es compatible con la sharía. La prohibición de maysir se ciñe a la obtención de beneficios mediante la suerte o especulación. De acuerdo con este precepto, los contratos de derivados que entrañan un fin especulativo son incompatibles con la sharía. En la práctica, la distinción entre especulación ilícita y riesgo empresarial legítimo puede ser difícil de trazar, especialmente en los casos de toma de participación en una sociedad con vistas a obtener un retorno en forma de dividendos. La prohibición de invertir en productos o actividades haram se refiere tradicionalmente a los juegos de azar, pornografía, carne de cerdo, alcohol e incluye por extensión, según algunos expertos islámicos, el tabaco, las armas de fuego, el cine y la música. En los últimos años es cada vez más frecuente que los expertos islámicos se pronuncien en contra de la inversión en actividades de seguros, de financiación convencional basada en tipos de interés y de intermediación financiera. La prohibición de invertir en productos o actividades haram se extiende, asimismo, a la inversión en inmuebles en los que pueda tener lugar el comercio sobre los mismos. En la práctica, dado el grado de diversificación e interconexión de las actividades empresariales, puede llegar a ser extraordinariamente difícil determinar en qué medida una empresa está involucrada en actividades haram. Los expertos islámicos han desarrollado técnicas de «tolerancia» y «depuración» de la inversión en productos $\mathrm{y}$ actividades haram basadas en el cumplimiento de ciertos requisitos, como por ejemplo que el negocio principal que es objeto de la inversión sea halal; que los beneficios obtenidos de actividades prohibidas representen un porcentaje comparativamente menor respecto del beneficio total obtenido -habitualmente entre el $5 \%$ y el $20 \%$, dependiendo del criterio del experto islámico en cuestión-; o que el importe total de la deuda sujeta al pago de intereses no exceda un determinado porcentaje del valor de los activos o capitalización bursátil de la sociedad -habitualmente entre el 25\% y el 35\%-.

(C) UNED. Revista de Derecho UNED, núm. 18, 2016 
tro de un proceso más amplio de 'islamización' del ordenamiento jurídico secular ${ }^{6}$. Este sería el caso de las monarquías del Consejo de Cooperación del Golfo (CCG), Mauritania, Sudán, Irán, Iraq, Afganistán, Paquistán, Brunéi, Malasia e Indonesia ${ }^{7}$.

No obstante, esta visión tradicional del derecho financiero islámico no acierta a describir un segundo fenómeno surgido de la moderna práctica financiera y que podríamos denominar con cierta cautela «responsabilidad corporativa islámica» ${ }^{8}$. La noción de derecho finan-

${ }^{6}$ Véanse como obras más representativas de este enfoque ANDERSON, N. (1976), Law Reform in the Muslim World, Londres: Athlone Press; NIENHAUS, V. (1996), "Islamische Ökonomik in der Praxis: Zinslose Banken und islamische Wirtschaftspolitik», pp. 175-185 en ENDE, W. / STEINBACH, U. / KRÜGER, G., Der Islam in der Gegenwart, 4. ${ }^{\text {a }}$ ed., Múnich: C. H. Beck; WARDE, I. (2000), Islamic finance in the Global Economy, Edimburgo: Edinburgh University Press, pp. 112-123.

${ }^{7}$ El grado de reconocimiento de la sharía como fuente del derecho en los ordenamientos jurídicos estatales oscila entre la falta total de reconocimiento -pensemos por ejemplo en Estados Unidos, los Estados miembros de la UE, Japón, Corea o China- y la designación como principal fuente del derecho- por ejemplo en los países del CCG, Mauritania, Sudán, Irán, Iraq, Afganistán, Paquistán, Brunéi o, en menor medida, Malasia e Indonesia-. También se encuentran diferencias notables en la aplicación de la sharía en aquellos países que han optado por adaptar sus ordenamientos jurídicos al Islam. A pesar de su reconocimiento como fuente del derecho en algunos casos, los estados han hecho -con la única excepción del derecho de familia y sucesiones- una selección extraordinariamente restrictiva de las normas de la sharía que pueden ser objeto de incorporación al ordenamiento jurídico estatal. Esta incorporación selectiva obedece a que las normas integrantes de la sharía fueron compiladas en la Alta Edad Media y su función y contenido han quedado en gran medida obsoletos. Es precisamente en el ámbito del derecho privado -exceptuando el derecho de familia y sucesiones- donde la vigencia de la sharía ha experimentado su declive más notable. Aunque es cierto que los Códigos civiles y mercantiles aprobados después de los procesos de descolonización en países de Oriente Medio incorporan algunos elementos propios de la sharía en materia de contratación privada -especialmente el Código civil de Jordania de 1976 y el Código civil de los Emiratos Árabes Unidos de 1985-, la mayor parte de los países de la región ha venido manteniendo o formando sus normas sobre obligaciones y contratos, responsabilidad civil y derecho societario sobre patrones occidentales -habitualmente franceses y británicos-, los cuales han devenido absolutamente irrenunciables en la actualidad para los actores de mercado que operan en ellos. Como botón de muestra, la famosa prohibición de riba o interés, que se considera la piedra angular del derecho financiero islámico, apenas forma parte de ningún ordenamiento secular. De ahí que se pueda afirmar que la industria financiera islámica opere actualmente en un contexto jurídico escasamente islamizado. Si las normas de contratación privada de los ordenamientos jurídicos estatales se hubieran islamizado plenamente, sería difícil imaginar la expansión de una industria financiera islámica alternativa a la práctica convencional. A este fenómeno se añade, además, la mayor implantación de la industria financiera islámica en países liberales con una clara separación de religión y estado.

${ }^{8}$ En el derecho islámico tradicional los actos humanos se pueden clasificar atendiendo a la validez jurídica de un acto -con pronunciamientos que van desde la calificación del acto como sahih (válido) hasta batil (nulo de pleno derecho)-, así como atendiendo a la religiosidad de este, cuya calificación oscila entre wadyib (obligato- 
ciero islámico entendido en este último sentido describe un compendio de buenas prácticas islámicas de adhesión voluntaria en materia de contratación bancaria, creadas y aplicadas al margen de los ordenamientos jurídicos seculares inspirados o no por la sharía. La llamada «resurrección de la sharía» en el ámbito del derecho financiero moderno describe precisamente la tarea desempeñada por expertos privados consistente en la selección y reinterpretación de principios y normas altomedievales con el fin de crear buenas prácticas contractuales de adhesión voluntaria en el tráfico bancario ${ }^{9}$. A priori, resulta sorprendente que el fenómeno del derecho financiero islámico así concebido sea más intenso en países liberales, que con cuentan una clara separación de religión y estado -por ejemplo Emiratos Árabes Unidos, Malasia y Reino Unido- que en aquellos estados cuyo ordenamiento jurídico se supone plenamente islamizado como Arabia Saudí, Sudán, Paquistán o Irán que, aunque cuentan con una industria financiera islámica propia, es escasamente atractiva para inversores internacionales ${ }^{10}$.

La delimitación del fenómeno que hemos denominado «responsabilidad corporativa islámica» arroja dos interrogantes difíciles de responder en el escenario actual. En primer lugar, se plantea la cues-

rio) y haram (prohibido). Llevado al terreno de las finanzas islámicas, allí donde los principios y normas de la sharía se han incorporado en el ordenamiento jurídico secular, la cuestión se reduce casi siempre a la calificación de la validez del acto conforme al derecho positivo (ipsa lex), llevada a cabo por un órgano jurisdiccional sin entrar en juicios de naturaleza religiosa. Sin embargo, allí donde los principios y normas islámicas forman un compendio de buenas prácticas, creado y aplicado al margen del estado nacional, la cuestión a dilucidar es si una operación es o no halal -reto que a su vez plantea otras preguntas como a quién encomendar la creación y la aplicación de esos compendios de buenas prácticas y cómo velar por su islamicidad-.

${ }^{9}$ En el contexto de las finanzas islámicas los principios y normas extraídos de la sharía son aplicados como principios y normas de carácter ético y no tanto jurídico. Habitualmente, el contrato de financiación estará sometido al ordenamiento jurídico secular de un determinado estado, operando la adhesión a la sharía como una manifestación de conformidad verificable ex ante por un experto islámico con renuncia expresa de las partes de invocar una eventual falta de conformidad en la vía contenciosa. La adhesión a la sharía responde al patrón habitual de la responsabilidad social corporativa, si entendemos por tal «el conjunto de obligaciones inherentes a la libre asunción de un estado o condición, aun no tipificado por el ordenamiento jurídico positivo, pero cuya fuerza vinculante y previa tipificación proceden de la íntima convicción social de que su incumplimiento supone la infracción de la norma de cultura», véase SOLANO SANTOS, L. F. (2006), Fundamentación lógico-formal de la responsabilidad social corporativa, pág. 70, tesis disponible en [En línea] http://biblioteca.ucm.es/tesis/inf/ucm-t29376.pdf.

${ }^{10}$ A la actividad de los expertos privados se une la tarea fundamental de bancos de inversión, compañías de auditores y despachos de abogados internacionales de crear modelos contractuales comúnmente aceptados en la práctica de mercado, como veremos más adelante. 
tión acerca de quiénes deben asumir la función de autoridades normativas competentes para crear $-\mathrm{O}$, mejor dicho, recuperar- y velar por la islamicidad de principios y normas en el ámbito del derecho financiero islámico. En segundo lugar, cabe preguntarse acerca de la metodología que deben seguir estas autoridades en la elaboración de las buenas prácticas islámicas ${ }^{11}$.

\section{a) Autoridades normativas}

Existen varias posiciones en relación con la primera cuestión. De acuerdo con la concepción más extremista, por cuanto la sharía no se pronuncia sobre la autoridad competente para su aplicación, cualquier musulmán estaría legitimado para llevar a cabo esta tarea ${ }^{12}$. De acuerdo con una posición más historicista, la interpretación de la sharía no correspondería a una autoridad política -tradicionalmente el Califa o, en la actualidad, los órganos del estado secular-, sino a las grandes escuelas jurídicas islámicas, en particular, a las cuatro tradicionales del ámbito suní ${ }^{13}$. Dado que dichas escuelas desaparecieron a finales del s. XVIII, la creación de la autoridad normativa pasaría por la revitalización o refundación de las cuatro escuelas o alguna de ellas. Las dos posiciones anteriormente descritas no gozan de mucho reconocimiento fuera del circuito académico. La incertidumbre generada por la ausencia de autoridades y metodologías normativas comúnmente aceptadas en la industria financiera islámica ha provocado que entidades de crédito, fondos de inversión, family offices y espónsores dedicados al desarrollo de productos financieros islámicos se decanten cada vez más por la contratación de agencias privadas de expertos islámicos y la solicitud de dictámenes ad hoc para evaluar la compatibilidad de una determinada operación con la sharía y, en particular, con ciertas escuelas de pensamiento suníes ${ }^{14}$. En la práctica

${ }^{11}$ Parafraseando con algo de ligereza la teoría del ordenamiento jurídico de Santi Romano, diremos que en este planteamiento resulta válido lo que en principio se nos presenta como una paradoja: el que la autoridad es tal en cuanto establece normas que suponen la exteriorización de la sharía, pero las normas exigen respeto en la medida en que son establecidas por la autoridad, actuando la sharía como fuerza unificadora de la autoridad y las normas que integran el ordenamiento islámico. Véase GARCÍA MIRANDA, C. M. (1998), «La unidad en el concepto de ordenamiento jurídico de Santi Romano", Anuario da Facultade de Dereito da Universidade da Coru$\tilde{n} a$, n. ${ }^{\circ}$ 2, p. 296.

${ }^{12}$ Véase KHALED, A. E. F. (2005), The Great Theft: Wrestling Islam from the Extremists, Harper Collins, p. 27.

${ }^{13}$ Aunque sin duda son muy relevantes, este trabajo no tiene por objeto las finanzas islámicas del ámbito chií.

${ }^{14}$ Acerca de los problemas derivados de la falta de uniformidad en la interpretación de la sharía aplicada a los mercados financieros, véase ASHRAF, U. K. / ABDEL, K. H. (2006), "The influence of Quran and Islamic financial transactions and ban- 
bancaria moderna, los dictámenes u opiniones legales jurídico-religiosos (fetuas o fatawa) son las principales fuentes de aplicación de los preceptos de la sharía en el tráfico financiero ${ }^{15}$. Las fetuas no suelen tener por objeto un pronunciamiento sobre la compatibilidad de una determinada operación con el derecho positivo, en mayor o menor medida islamizado, de un determinado estado -por ejemplo, las normas de contratación bancaria de Arabia Saudí-, sino con el derecho financiero islámico entendido como conjunto de buenas prácticas contractuales comúnmente aceptadas en el tráfico -con las dificultades de identificación de la norma que ello conlleva-. La necesidad de solicitar dictámenes ha dado lugar al nacimiento de una verdadera industria de agencias especializadas en el asesoramiento sobre la sharía (Shari'a boards). Además de la emisión de fetuas, las funciones habituales de los expertos islámicos se centran en la participación en el diseño de productos financieros así como en la revisión y aprobación de estructuras societarias y contractuales. Es cada vez más frecuente que los expertos lleven a cabo un monitoreo de las prácticas comerciales de la empresa -el denominado Islamic compliance- y elaboren cartas de confirmación de cumplimiento para su inclusión en las cuentas anuales ${ }^{16}$. La elaboración de dictámenes por los Shari'a boards se ve complementada con la actividad de despachos de abogados, compañías de auditoría y bancos de inversión que diseñan esquemas de financiación compatibles con la sharía. Este planteamiento es coherente con la idea de que el derecho financiero islámico no es más que un cuerpo de principios de 'responsabilidad corporativa islámica' al que las partes se adhieren voluntaria e independientemente de la designación de la ley aplicable al contrato. En los contratos de finan-

king», Arab Law Quarterly, vol. 20, n. ${ }^{\circ}$ 3, p. 329; FOSTER, N. H. D. (2007), «Islamic Finance as an emergent legal system», Arab Law Quarterly, vol. 21, n. ${ }^{\circ}$ 2, pp. 170-188.

${ }^{15}$ La emisión de dictámenes no representa una práctica de precedentes jurisprudenciales. En el ámbito del derecho islámico es muy poco frecuente la utilización de precedentes jurisprudenciales debido a que, oficialmente, no existen órdenes jurisdiccionales habilitados para emitir pronunciamientos sobre la sharía y a que la noción de precedente jurisprudencial constituye un anatema -los jurisconsultos no pueden crear leyes, tarea reservada a Dios, sino únicamente descubrir el significado ya existente mediante el estudio y la investigación-.

${ }^{16}$ Son apenas 20 expertos islámicos en todo el mundo quienes dominan los Shari'à boards que asesoran regularmente a las entidades de crédito más importantes. Entre ellos destacan Yusuf Talal DeLorenzo, Sheikh Nizam Yaqubi, Muhammad Taqi Usmani, Sheikh Yusuf al-Qaradawi y Mohammad Akram Nadwi. Acerca de la industria de agencias de expertos islámicos, véase POWER, C. (2009), "Faith in the market», Foreign Policy, n. ${ }^{\circ}$ 170, enero-febrero, pp. 70-75. Acerca de los problemas derivados de los frecuentes conflictos de interés, véase HEGAZY, W. (2005), «Fatwas and the Fate of Islamic Finance: A Critique of the Practice of Fatwa in Contemporary Islamic Financial Markets», en ALI, S. N. (2005), Islamic Finance, Current Legal and Regulatory Issues, Harvard Law School, Cambridge, p. 133. 
ciación islámicos modernos es habitual pactar como ley aplicable la del Reino Unido o del estado de Nueva York, «con sujeción a los principios de la gloriosa sharía» ${ }^{17}$. A pesar de lo que pueda sugerir su tenor literal, la intención de las partes contratantes en este tipo de cláusulas es someter el conocimiento del contrato a las leyes de una jurisdicción occidental de reconocido prestigio en el tráfico financiero -cuyos órganos jurisdiccionales declinarán previsiblemente todo pronunciamiento en materia religiosa- y encomendar a un Shari'a board designado de común acuerdo entre las partes la verificación ex ante del cumplimiento de ciertos principios islámicos -esto es, con anterioridad a la suscripción del contrato y en ningún caso en la vía contenciosa- ${ }^{18}$. Asimismo, el Shari'a process de una operación da cierta 'seguridad moral' a los partícipes islámicos más observantes, en la medida en que un experto islámico emite una fetua que se pronuncia ex ante y específicamente sobre la islamicidad de una determinada operación, lo que redunda a su vez en cierta seguridad jurídica de los partícipes convencionales, en la medida en que logran acotar de antemano parte de los posibles conflictos con los partícipes observantes en la operación.

El riesgo de que un órgano jurisdiccional estatal decida pronunciarse sobre cuestiones religiosas y, eventualmente, realice una interpretación distinta a la esperada en la práctica de mercado convencional recibe la denominación de Shari'a risk, riesgo que los operadores desean por supuesto evitar. Este riesgo resulta aún más acuciante si el contrato queda sometido a las leyes de un estado que ha incorporado la sharía como fuente del derecho de su ordenamiento jurídico; pensemos en los ya mencionados países del CCG, Mauritania, Sudán, Irán, Iraq, Afganistán, Paquistán, Brunéi, Malasia e Indonesia. No resulta sorprendente que sea precisamente en estas jurisdicciones donde el derecho financiero islámico entendido como 'responsabilidad corporativa islámica' goce de menor implantación y, sin embargo, prospere en jurisdicciones con una clara separación de religión y estado. Con el fin de prevenir el riesgo de 'judicialización' del derecho

${ }^{17}$ Véase la cláusula de sumisión del caso Shamil Bank of Bahrain EC v. Beximco Pharmaceuticals Ltd. citado infra: "Subject to the principles of the glorious Shari'a, this Agreement shall be governed by and construed in accordance with the laws of England».

${ }^{18}$ Retomando la dicotomía antes referida entre la validez jurídica de un acto y la calificación religiosa de este, podríamos decir que los operadores del mercado prefieren atribuir el conocimiento de la validez a los órganos jurisdiccionales estatales, que, como hemos visto, rara vez se encuentran en países islámicos, y encomendar la calificación religiosa a un experto islámico, evitando en la medida de lo posible el riesgo de su judicialización. 
financiero islámico es cada vez más habitual que las partes contratantes estipulen una cláusula denominada "waiver of Shari'a defense», esto es, una renuncia de las partes a invocar la falta de conformidad del contrato con los preceptos islámicos ${ }^{19}$. En línea con esta idea, el derecho financiero islámico es percibido más como un "riesgo" para el éxito de una operación de financiación que como una 'norma', cuya función primordial debiera ser precisamente la de dar seguridad a la operación. Frente a este riesgo, la emisión de dictámenes por agencias privadas genera seguridad jurídica en el tráfico -entendida como congruencia con la sharía de un esquema de financiación cuyo contenido económico responde, en el fondo, a la práctica financiera convencional-, con la ventaja añadida de que la obtención del dictamen facilita la inclusión de la cláusula "waiver of Shari'a defense» en el contrato, eliminando de antemano, o al menos en teoría, el riesgo de judicialización de las cuestiones religiosas ${ }^{20}$.

\section{b) Metodología de creación de normas}

La segunda pregunta que nos planteamos es cuál debe ser la metodología a seguir por la autoridad normativa -en la práctica financiera actual, los comités y agencias de expertos islámicos antes indicados- para recuperar y aplicar una norma inspirada en la sharía. Como punto de partida, conviene recordar que el contenido de gran parte de las normas compiladas por los juristas del periodo califal y que se ha dado en denominar sharía no sólo ha devenido obsoleto sino que además ha caído en el olvido fuera de los círculos de especialistas $^{21}$. Aun en los países más intensamente islamizados, la práctica financiera sería inconcebible sin la incorporación y el predominio de

${ }^{19}$ Véase BÄLZ, K. (2008), «Sharia Risk: How Islamic Finance has transformed Islamic Contract Law», Harvard Law School, Islamic Legal Studies Program, Occasional Publications 9, septiembre, disponible en http://www.law.harvard.edu/programs/ ilsp/publications/balz.pdf (último acceso 14/12/2015).

${ }^{20}$ Un ejemplo de cláusula de waiver of Shari'a defense podría ser el siguiente: «The transaction contemplated in this Agreement has been approved by [Sharia board], whose ruling with regard to Sharia matters shall be final and binding for the Parties. Neither Party shall be entitled to raise any objections or defenses based on the basis that the Agreement, the transaction envisaged therein or certain clauses contained therein, is not in compliance with the principles of Islamic Sharia (Waiver of Sharia Defense)».

${ }^{21}$ A esta se añaden otras dificultades como la fragmentación de la sharía en el periodo clásico y la notable ausencia de fuentes escritas fuera del Imperio Otomano del s. XIX. Aún en el caso de que fuera posible, la recuperación de legislación y práctica comercial de la sharía presenta problemas metodológicos como por ejemplo la práctica de hiyal, propia de la influyente escuela Hanafí, que permite validar negocios jurídicos prohibidos mediante ficciones jurídicas, y que hoy sería considerada un fraude de ley incompatible con una interpretación 'pura' de la sharía. Véase FOSTER, 
las instituciones jurídico-privadas de corte occidental. A partir de esta premisa, parece ampliamente admitido entre los operadores del mercado que la revitalización del derecho financiero islámico no debe aspirar a una restauración in toto de la compilación de normas del periodo medieval, sino más bien a una selección de normas medievales compatibles con el tráfico financiero moderno. De ahí que la tarea de los expertos islámicos de 'revivir' ciertas normas de la sharía para evitar así su olvido y obsolescencia -inspirada, en principio, por una Weltanschauung religiosa-, se vea fuertemente limitada por el corsé de la práctica financiera convencional ${ }^{22}$. La actividad de selección de normas plantea problemas teóricos complejos y da lugar a más de alguna incoherencia. Por citar sólo un ejemplo: la indiscutible prohibición de productos financieros sujetos a un tipo de interés y la no tan reprobable personalidad jurídica de las personas morales -figura igualmente prohibida en la sharía- ${ }^{23}$.

En la doctrina se encuentran tres posiciones principales acerca de la metodología a seguir en la recuperación y aplicación de las normas del moderno derecho financiero islámico. En primer lugar están los

N. H. D. (2007), «Islamic Finance as an emergent legal system», Arab Law Quarterly, vol. 21, n. $^{\circ} 2$, p. 178 .

${ }^{22}$ La necesidad de legitimación religiosa de las prácticas comerciales convencionales no es novedosa ni exclusiva del Islam. En el contexto cristiano católico, el jesuita flamenco Leonardo Lessio defiende a principios del s. XVII la utilización de esquemas contractuales complejos como el 'contractus trinus' con el fin de evitar la prohibición de la usura y balancear eficiencia económica y legitimidad moral (véase De Iustitia et iure, 1605). Un estudio exhaustivo de la figura de Lessio y las figuras de 'societas' y 'contractus trinus' puede encontrarse en DECOCK, W. (2012), «In Defense of Commercial Capitalism: Lessius, Partnerships and the Contractus Trinus», Max Planck Institute for European Legal History, Research Paper Series, no. 2012-04, disponible en SSRN http://ssrn.com/abstract=2162908.

${ }^{23} \mathrm{Al}$ margen de los planteamientos anteriores, merece la pena destacar la posición del profesor El Gamal, quien se muestra muy crítico con la elaboración e interpretación de modelos de contratos bancarios por expertos privados a partir de una recepción nominalista y utilitarista de las escuelas de pensamiento suníes. Sostiene que la 'privatización' del derecho financiero islámico tiene como principales perjudicadas a las clases desfavorecidas del mundo islámico. Su propuesta pasa por abandonar la concepción del derecho financiero islámico como mero mecanismo de traslación más o menos artificioso, pero acrítico en el fondo- de los esquemas de financiación convencionales, para crear un nuevo paradigma de selección de normas basado en el mandato coránico de justicia (' $a d l$, لد ع), entendido aquí como generosidad con los pobres. La clave de bóveda de las propuestas de El Gamal se encuentra en la articulación de cooperativas de microcréditos basadas en la institución coránica de waqf. Véase EL GAMAL, M., "Exploitative Profit Sharing: On the incoherence of all contract-based approaches to «Islamic finance», http://elgamal.blogspot.com.es/ (último acceso 12/12/2015); HAMOUDI, H. A. (2011), «Present at the resurrection: Islamic Finance and Islamic Law», American University International Law Review, vol. 26, no. 4, pp. 1107-1123. 
partidarios de recuperar las normas creadas por una de las cuatro escuelas de pensamiento suníes y desechar las demás. En contra de esta posición se suele esgrimir que la restauración acrítica de una sola escuela limitaría extraordinariamente la cantidad y calidad del elenco de normas recuperables y reduciría sensiblemente la legitimidad del derecho financiero islámico en aquellas zonas geográficas en las que predominan otras escuelas ${ }^{24}$. Una segunda posición sostiene que el acervo jurídico de las cuatro escuelas de pensamiento debiera ser objeto de reordenación y refundición. En la actualidad, este método es el que goza de más aceptación entre las agencias especializadas de expertos islámicos. No obstante, algunos críticos sugieren que, desde un punto de vista teórico, parece difícil justificar la fusión artificial de cuatro cuerpos doctrinales que fueron elaborados en su momento con arreglo a metodologías muy distintas. También se suele esgrimir que la combinación de las diferentes tradiciones obedece a fines estrictamente utilitaristas -en el caso de los expertos islámicos, la mejor adecuación de una determinada norma a las exigencias del moderno tráfico financiero-, objetivo que va en detrimento de la elaboración de un cuerpo de normas coherente bajo un punto de vista dogmático-religioso. La tercera posición, con cierto predicamento en círculos académicos, pero difícil de aceptar en los sectores más conservadores del tráfico financiero, consiste en abandonar las cuatro escuelas medievales y reinterpretar la sharía conforme a métodos contemporáneos ${ }^{25}$.

c) La lex mercatoria islámica como práctica jurídica transnacional

La monopolización del derecho financiero islámico por agencias privadas ha dado lugar a problemas de parcialidad, tacticismo, opinion shopping y conflictos de interés, además de validar la utilización de esquemas de financiación que dan un cumplimiento meramente formal a los preceptos islámicos ${ }^{26}$. Desde el punto de vista de la certi-

${ }^{24}$ Las escuelas jurídicas suníes desaparecieron como instituciones a finales del s. XVIII, pero su legado doctrinal pervive en la actualidad. La escuela 'Hanafí' representa la principal escuela de los musulmanes suníes y predomina en el sur y centro de Asia; la "Shafí» es la segunda escuela más difundida y predomina en los países musulmanes del Sudeste Asiático; la «Malikí» predomina en el Magreb; y la «Hanablí» predomina en la península arábiga. Véase SCHACHT, J., "The Schools of Law and later developments in jurisprudence» en KHADDURI, M. / LIEBESNY, H. J. (2010), Law in the Middle East, Washington D. C., pp. 57-84.

${ }^{25}$ Este proceso fue descrito por primera vez por el pensador sirio Abd al-Rahman al-Kawakibi (1855-1902) con una imagen ya célebre como «la reapertura de puertas de la ichtihad» (reopening the gates of ijtihad).

${ }^{26}$ Aunque este tema daría para una exposición mucho más amplia, véase EL GAMAL, M., «Exploitative Profit Sharing: On the incoherence of all contract-based 
dumbre y la uniformidad del derecho financiero islámico, resulta además problemático -aunque lógico- que las fetuas estén sometidas a cláusulas de confidencialidad, obstaculizando así el desarrollo y generalización de prácticas comerciales comunes en los mercados financieros islámicos. Con el fin de prevenir los efectos perversos antes indicados y, en general, de reducir los costes de transacción derivados de la falta de certidumbre y uniformidad, en los últimos años se han creado comités de expertos en diferentes instituciones con el fin de estandarizar y promocionar las buenas prácticas islámicas. Entre las instituciones más destacables se encuentran el Instituto de Investigación Islámica (Mayma' al-Buhuth al-Islamiyyah) de la Universidad Al-Azahr de El Cairo ${ }^{27}$, la Organización de Contabilidad y Auditoría para Instituciones Financieras Islámicas (Accounting and Auditing Organization for Islamic Financial Institutions, AAOIFI) ${ }^{28}$, la Institución para el Mercado Financiero Islámico Internacional (International Islamic Financial Market, IIFM) ${ }^{29}$, la Academia Islámica de Fiqh (Madyma'al-Fiqh al-Islamy-l-Douwalî) perteneciente a la Organización para la Cooperación Islámica (OIC) ${ }^{30}$, el Instituto Islámico de Jurisprudencia (Al-Mayma' Al Fihi Al Islami) de la Liga Mundial Islámica (Rabita al-Alam al-Islami) ${ }^{31}$, el Banco Islámico de Desarrollo (Islamic

approaches to «Islamic finance» (29/01/2014): «My point has been, and continues to be, that there is no amount of juristic (fiqhi) analysis of contract forms that will help you determine whether or not there is injustice in the exchange, and that is the crux of the matter for calling something «Islamic,» because the first requirement is Justice ('adl, لעد); http://elgamal.blogspot.com.es/ (último acceso 12/12/2015). Véase a este respecto la discusión entre Mahmoud El Gamal y Kilian Bälz, ferviente defensor de la actividad de los expertos privados, en el marco del XVIII Congreso de la International Academy of Comparative Law que tuvo lugar el 27 de julio de 2010, transcrita en HAMOUDI, H. A. (2011), «Present at the resurrection: Islamic Finance and Islamic Law», American University International Law Review, vol. 26, no. 4, pp. 1107-1123.

${ }^{27}$ Creado en 1961, constituye la primera institución de este tipo.

${ }^{28}$ Con sede en Baréin: http://aaoifi.com. Véase la publicación en mayo de 2015 de los nuevos principios contables aplicables a la mudaraba (Accounting standard on investment accounts - Financial Accounting Standard No. 27 (FAS 27).

${ }^{29}$ Con sede en Baréin: http://www.iifm.net/about_iifm/shariah-advisory-panel. Entre sus actividades más destacables está la suscripción de un memorando de entendimiento el 30 de enero de 2007 con la International Capital Markets Association acerca de la estandarización de sukuk.

${ }^{30}$ Con sede en La Meca (Arabia Saudí): http://www.fiqhacademy.org.sa/. De acuerdo con el profesor El Gamal, la jurisprudencia de esta institución es la más ampliamente citada en el tráfico financiero islámico. Véase EL GAMAL, M. A., «Interest and the Paradox of Contemporary Islamic Law and Finance», Fordham International Law Journal, n. ${ }^{\circ} 108,2003$, p. 114.

${ }^{31}$ Con sede en Yeda (Arabia Saudí): http://www.themwl.org/Fatwa/default. aspx?l=En. 
Development Bank) ${ }^{32}$, la Agencia Islámica Internacional de Rating (International Islamic Rating Agency, IIRA) patrocinada por el Banco Islámico de Desarrollo ${ }^{33}$, el Banco Central de Malasia (Bank Negara Malaysia) ${ }^{34}$, la Comisión del Mercado de Valores de Malasia (Suruhanjaya Sekuriti) ${ }^{35}$ y el Comité de Servicios Financieros Islámicos (Islamic Financial Services Board, IFSB) ${ }^{36}$, por citar sólo las más relevantes. Las directrices y recomendaciones de AAOIFI, IIFM e IFSB gozan ya de una amplia reputación en la práctica financiera.

Los Shari'a standards elaborados por estas instituciones -notablemente la AAOIFI- constituyen declaraciones de principios, cuya finalidad es ayudar a calificar la islamicidad de una operación de financiación. Estos estándares están concebidos para su utilización por expertos islámicos en la fase de negociación de una operación proyectada, esto es, ex ante, antes de la suscripción del contrato. No constituyen codificaciones o compilaciones de normas bancarias que puedan servir a la integración del contrato en caso de disputa entre las partes; por ejemplo, en caso de incumplimiento ${ }^{37}$. Esta aproximación de las autoridades regulatorias es coherente con la idea de que el contrato de financiación islámico debe ser diseñado con arreglo a la sharía, pero estar sometido a la ley de una jurisdicción de reputado prestigio, elección que se procura proteger con la cláusula waiver of

${ }^{32}$ Con sede en Yeda (Arabia Saudí): http://www.isdb.org/. El Banco Islámico de Desarrollo tiene una división de auditoría y contabilidad y un Sharía board, que aprueban y actualizan regularmente los denominados Accounting, Auditing, and Governance Standards for Islamic Financial Institutions y Shari'a Standards.

${ }^{33}$ Con sede en Baréin: http://www.iirating.com. Entre sus miembros están el Banco Islámico de Desarrollo, la Islamic Corporation for the Development of the Private Sector, dos agencias de calificación islámicas y varias entidades financieras.

${ }^{34}$ Con sede en Kuala Lumpur (Malasia): http://www.bnm.gov.my/.

${ }^{35}$ Con sede en Kuala Lumpur (Malasia): http://www.sc.com.my/.

${ }^{36}$ Con sede en Kuala Lumpur (Malasia): http://www.ifsb.org/. El IFSB cuenta entre sus miembros a entidades financieras, bancos centrales nacionales y organizaciones financieras internacionales como el Fondo Monetario Internacional, Banco Mundial y Banco de Pagos Internacionales. Hasta la fecha ha aprobado dos documentos denominados, respectivamente, Guiding Principles of Risk Management y Capital Adequacy Standard for Institutions (Other than Insurance Institutions) Offering only Islamic Financial Services, ambos de 2005.

${ }^{37}$ Algunos autores citan como ejemplo de compilación de normas de contratación bancaria islámica la ley modelo de banca islámica (Model Islamic Banking Act) elaborada en 1977 por la International Association of Islamic Banks en cooperación con expertos destacados en finanzas islámicas y en derecho comparado. La ley modelo se centra en problemas propios de la banca islámica (artículos 1 a 10) y en problemas comunes a todos los bancos (artículos 11 a 20). Sin embargo, la ley modelo representa más un patrón de ley de ordenación de entidades de crédito islámicas que una verdadera compilación de normas de contratación bancaria. En tanto que ley de ordenación, ha tenido cierta influencia en las leyes de ordenación bancarias aprobadas en Malasia, Egipto y Paquistán en los años 1980. 
Shari'a defense, que pretende evitar la dilucidación de cuestiones religiosas en la vía contenciosa.

Como fenómeno global, las finanzas islámicas encajan mal con la teoría clásica del derecho comparado ${ }^{38}$. La estandarización a través de prácticas jurídicas transnacionales parece ofrecer un mejor paradigma metodológico, si bien conviene hacer dos precisiones ${ }^{39}$. De un lado, las operaciones de financiación islámicas suelen desarrollarse en jurisdicciones muy distintas entre sí, algunas de ellas muy poco sofisticadas, cuyos ordenamientos pueden ser de matriz common law -como Malasia- o continental -como los Emiratos Árabes Unidos ${ }^{40}$-, lo que reduce sus posibilidades de uniformización. De otro lado, la interpretación de la sharía que hacen autoridades regulatorias y agencias de expertos islámicos varía mucho según la región. Así, por ejemplo, los operadores de Malasia, India o Indonesia tienden a ser bastante más 'liberales' que sus equivalentes en el CCG o Paquistán. Estas diferencias han dado lugar al desarrollo de ciertas prácticas de mercado propias de Oriente Medio y del Sudeste Asiático, las cuales a su vez no representan la opinión unánime de todos los operadores que actúan en esos mercados ${ }^{41}$. De ahí que, en el contexto de las finanzas islámicas entendidas como fenómeno global, no podamos, de momento, validar la teoría del derecho comparado según la cual las prácticas jurídicas

${ }^{38}$ En los últimos años la globalización ha puesto en tela de juicio aquel paradigma tradicional de la teoría del derecho comparado de «escrutar las diferencias y semejanzas de las instituciones propias de ordenamientos jurídicos distintos»; planteamiento que -en términos de Ulrich Beck- respondería a una teoría del contenedor, según la cual los estados nacionales y sus ordenamientos jurídicos positivos son aislables y contenibles en "cajas» (véase BECK, U. (2000), What is globalization?, UK: Polity Press, Cambridge). Vemos que la teoría del derecho comparado presta cada vez más atención a los fenómenos denominados prácticas jurídicas transnacionales, esto es, principios y normas generados en el mercado internacional al margen de los estados nacionales y únicamente refrendados tácitamente por éstos. Desde esta perspectiva, el derecho internacional de los negocios no sería más que un conjunto de principios y normas definidos en contratos y estandarizados progresivamente por la práctica de mercado. Esta perspectiva es útil a la hora de abordar la delimitación de la naturaleza del derecho financiero islámico, dado que permite apartarnos del paradigma tradicional estado-céntrico de la reforma normativa en el mundo musulmán. No obstante, veremos que, en el contexto de las finanzas islámicas, algunos postulados propios del debate sobre las prácticas jurídicas transnacionales deberán ser revisados, por ejemplo, la creencia de que la práctica jurídica transnacional tiende inexorablemente a la uniformización y que no es susceptible de cierto pluralismo regional.

${ }^{39}$ Aun así la estandarización a través de precedentes y colecciones de modelos contractuales (shurut) no es en absoluta ajena a la tradición islámica.

${ }^{40}$ Con la excepción notable del Dubai International Finance Centre (DIFC), vid. infra.

${ }^{41}$ Véase la disputa que tuviera lugar en 2008 a propósito de la islamicidad de las emisiones de sukuk. 
transnacionales tienden inexorablemente a la uniformización y observemos, al contrario, cierta cristalización de diferencias regionales no exentas de polémica ${ }^{42}$. Esta falta de uniformización posiblemente esté ligada al hecho de que autoridades regulatorias y agencias de expertos islámicos no aspiren a codificar verdaderas normas de contratación bancaria islámica, sino a formular principios que, en palabras de Dworkin y Alexy, representarían la «estructura profunda del derecho», situada en un plano distinto al de las normas, y que actúan como estándares prima facie que admiten varios resultados posibles en la medida en que sirven al operador jurídico para encontrar la norma más adecuada a cada supuesto ${ }^{43}$. Sería más adecuado hablar, por tanto, de finanzas islámicas como conjunto de prácticas jurídicas regionales armonizables en el plano de los principios.

\section{ESQUEMAS DE FINANCIACIÓN ISLÁMICOS}

El Islam tiene por relación contractual ideal aquélla en la que las partes gozan de igual exposición al riesgo inherente al negocio. De ahí que un aspecto clave del derecho financiero islámico sea la distribución equitativa de las pérdidas y ganancias entre partes financieras y financiadas. Las dos técnicas que mejor responden a esta concepción de la asunción del riesgo de negocio son la mudaraba ${ }^{44}$ y la musa-

${ }^{42}$ La aprobación o rechazo de una operación de financiación puede depender de la formación y el origen geográfico de los expertos, lo que no deja de causar perplejidad en los operadores internacionales. Véase BIANCHI, R. R., "The Revolution in Islamic Finance», Chicago Journal of International Law, vol. 7 n. ${ }^{\circ} 2$, 2007, p. 574, CANALEJO LASARTE, G. / CABELLOS BALLENILLA, A., "Apuntes sobre los contratos «islámicos» de financiación desde la perspectiva del derecho español», Actualidad Jurídica Uría Menéndez, n. ${ }^{\circ}$ 23, 2009, p. 28.

${ }^{43}$ DWORKIN, R. (2006), Taking rights seriously, Harvard University Press, Cambridge, 1978; ALEXY, R. (2006), Theorie der Grundrechte, Suhrkamp Verlag GmbH, Berlin.

${ }^{44}$ La mudaraba representa una de las formas de financiación más populares y se emplea para una amplia gama de actividades de negocio. La mudaraba es un acuerdo entre un inversor ( $r a b$ al-mal) y un gestor (mudareb), en virtud del cual el inversor constituye un fondo por un corto o medio plazo mediante la contribución de una aportación dineraria o no dineraria, que es administrado por el gestor bajo la supervisión del inversor para la promoción de una determinada actividad económica, con la obligación, al término del plazo pactado, de disolver el fondo, restituir -siempre que no hubiera quedado disminuida por las pérdidas- la aportación al inversor y repartir entre el inversor y el gestor las ganancias al 50\% o -en su caso- con la obligación del inversor de enjugar las pérdidas hasta el importe de la aportación, salvo que medie dolo o culpa del gestor. La mudaraba permite multitud de pactos entre las partes con respecto al negocio que es objeto de financiación, la duración, el capital aportado o el porcentaje de participación. Conviene destacar que la mudaraba es un negocio jurídico que presenta un alto riesgo para el inversor, por lo que es habitual

(C) UNED. Revista de Derecho UNED, núm. 18, 2016 
raka ${ }^{45}$, asimilables -no idénticas- a un contrato de cuenta en participación y a un contrato de joint venture, respectivamente. Dado que la asunción de todo o parte del riesgo empresarial por parte de los acreedores encaja mal con los esquemas de financiación convencionales, algunas técnicas de financiación islámica son adaptaciones de estándares internacionales, pero sin perder su compatibilidad con la sharía. Entre los esquemas contractuales adaptados destacan la $m u$ rabaha (comisión de compra y compraventa), istisna'a (contrato de obra $)^{46}$ e iyara (arrendamiento) ${ }^{47}$. La forma de emisión de deuda me-

que el inversor asegure el riesgo de crédito del gestor y la viabilidad de la actividad económica financiada mediante cláusulas de manifestaciones y garantías (representations and warranties) y delimite los supuestos de responsabilidad del gestor a través de obligaciones a futuro del gestor (covenants).

${ }^{45}$ La musaraka presenta algunas similitudes con la mudaraba. Se trata de un acuerdo concertado entre dos o más inversores, en virtud del cual constituyen una comunidad de bienes o una sociedad mediante la contribución de aportaciones de capital, que es administrada por todos o algunos de ellos o por un tercero designado al efecto para la promoción de una determinada actividad económica, con la obligación, al término del plazo pactado, de disolver la comunidad de bienes o la sociedad, restituir-siempre que no hubieran quedado disminuidas por las pérdidas- las aportaciones realizadas y haciéndose partícipes de sus resultados, prósperos o adversos, en la proporción y hasta el importe de la aportación realizada. Por su relevancia en el tráfico merecen especial consideración las denominadas musaraka «continua» y «decreciente». En la musaraka continua (en inglés, continuous musharaka) cada uno de los inversores mantiene su participación en la comunidad de bienes o sociedad hasta la expiración del plazo por el que fue constituida. En la musaraka decreciente (en inglés, diminishing musharaka) algunos inversores se obligan a vender todo o parte de su cuota en la comunidad de bienes o sociedad a otros inversores a un precio preestablecido.

${ }^{46}$ La istisna'a opera de forma similar a la murabaha. La istisna'a es un contrato de obra, en virtud del cual un promotor encomienda a un contratista -que en numerosas ocasiones es una entidad financiera- la construcción o fabricación de un determinado activo y se obliga a adquirirlo por un precio que puede ser abonado en la fecha de suscripción del contrato, en una fecha posterior o, más habitual, de acuerdo con un calendario de pagos que refleja los hitos de construcción o fabricación del activo. A diferencia de la murabaha, en la istisna'a el activo ni existe ni se encuentra en posesión del contratista en la fecha de suscripción del contrato, lo que supone una excepción notable al principio de prohibición de garar (incertidumbre). Las partes pueden resolver unilateralmente el contrato antes de que el contratista haya comenzado la construcción o fabricación del activo. El promotor no está obligado a adquirir el activo si éste no satisface las especificaciones del contrato. Con frecuencia, cuando el contratista es una entidad financiera, el contrato de istisna'a viene acompañado de un segundo contrato de istisna'a entre la entidad financiera y un verdadero contratista, al que encomienda la construcción o fabricación del activo. En ocasiones, en lugar de entregar el activo directamente al promotor en la fecha de finalización de la obra, las partes optan por que el contratista le arriende el activo al promotor de acuerdo con un contrato de iyara. La istisna'a es muy frecuente en el marco de la financiación de proyectos, especialmente en el caso de proyectos 'llave en mano' de infraestructuras, desarrollos urbanísticos y bienes de transporte como buques y aeronaves.

${ }^{47}$ En sentido amplio, la iyara describe un contrato de arrendamiento en virtud del cual el arrendador cede el uso de un activo o presta un servicio a cambio de una ren- 


\section{jor adaptada es el sukuk, que funciona de forma similar a un bono de} titulización ${ }^{48}$.

ta (uyra). En el contexto de las finanzas islámicas, la iyara suele configurarse bien como arrendamiento de uso de un activo en sentido estricto, en cuyo caso el activo es devuelto al término del contrato por el cliente a la entidad financiera, o bien como un contrato de arrendamiento combinado con un derecho de adquisición de la propiedad del activo. En este último caso, existe una modalidad denominada iyara muntahia bittamleek, asimilable a un contrato de arrendamiento financiero o leasing, en virtud del cual una entidad financiera se obliga a adquirir un activo con arreglo a las instrucciones de un cliente y a arrendar, a continuación, dicho activo al cliente por una renta equivalente al precio de adquisición más un margen previamente establecido, que es satisfecha de acuerdo con un calendario de pagos que contempla el abono de cuotas comprensivas de la parte prorrateada del precio de adquisición original y el margen. Es importante destacar que la opción de compra debe configurarse como negocio jurídico autónomo completamente desvinculado del negocio jurídico de arrendamiento y que el propietario arrendador asume íntegramente los riesgos jurídicos y económicos de la propiedad del activo, sin que quepan cláusulas de transmisión o distribución del riesgo con el arrendatario. Otro subtipo de iyara con adquisición del derecho de propiedad es el denominado iyara-wa-iqtina'a que contempla la transmisión de partes alícuotas del derecho de propiedad sobre el bien durante el plazo del contrato. En el contexto de la financiación de proyectos es relativamente frecuente la modalidad iyara mawsufa fi al-dhimma, que describe un contrato de arrendamiento con puesta a disposición diferida del activo en una fecha futura, que sin embargo sólo es válido si la renta comienza a devengarse a partir de la fecha de puesta a disposición.

${ }^{48}$ Los sukuk representan en la actualidad el instrumento financiero islámico con mayor arraigo en el tráfico. Los sukuk se pueden definir como valores de renta fija en forma de cuotas de participación sobre un activo subyacente -que puede ser tangible o intangible-, emitidos en serie con idéntico valor nominal, con una remuneración vinculada a los beneficios generados por el activo subyacente, susceptibles de representación mediante títulos valor o anotaciones en cuenta libremente transmisibles en mercados secundarios oficiales. Aunque habitualmente el término sukuk se suele traducir por «bonos islámicos» (Islamic bonds), lo cierto es que guardan mayor similitud con los certificados fiduciarios o bonos de titulización cuya rentabilidad está ligada a la evolución del valor de un activo subyacente que con las obligaciones convencionales cuyo retorno se enmarca en un calendario periódico de pagos de intereses fijos o variables. La operación de emisión de sukuk es un esquema de financiación en virtud del cual una entidad vehículo -generalmente un trust-emite sukuk para la suscripción por un colectivo de bonistas y emplea los fondos obtenidos de la suscripción de sukuk para abonar el precio compraventa de un determinado activo, constituir un fondo o comunidad de bienes o realizar una inversión en el negocio de un tercero. Se comprende, a partir de esta definición, que la emisión de sukuk aparezca generalmente vinculada a contratos de iyara, mudaraba o musaraka que generan retornos sobre un activo subyacente. La sukuk-aliyara es un esquema de financiación en virtud del cual el promotor vende ciertos activos halal a una entidad vehículo, constituida por el promotor a este efecto, que acuerda la emisión de sukuk, emplea los fondos obtenidos de los bonistas en la suscripción de sukuk para abonar el precio de compra de los activos y concierta un arrendamiento financiero con un tercero, que establece la cesión del uso del activo al tercero y el otorgamiento por el tercero de una opción de venta del activo a favor de la entidad vehículo, que podrá ejercitar en la fecha de amortización ordinaria o anticipada de la emisión de sukuk. En la sukuk-al-mudaraba se prevé la suscripción 
En la actualidad, el 80\% de las operaciones financieras compatibles con la sharía se realizan en forma de murabaha, por lo que vamos a detenernos un poco más en el estudio de esta figura y su problemática bajo el punto de vista de la ley aplicable, tanto en los casos de sumisión a la ley de un determinado ordenamiento jurídico como en los casos de falta de sumisión expresa. La murabaha se desdobla en un contrato de comisión de compra y dos contratos de compraventa, que tienen lugar de forma consecutiva ${ }^{49}$. De acuerdo con el contrato de comisión de compra, un cliente, que desea adquirir un determinado activo, encomienda a una entidad financiera la adquisición de dicho activo, que lo adquiere de acuerdo con el 'primer contrato de compraventa' por un precio « $\mathrm{X}$ » de un determinado proveedor y con sujeción a los términos y condiciones previamente acordados entre el proveedor y el cliente, que actúa como comisionista de la entidad financiera ${ }^{50}$. A continuación, con arreglo

de un contrato de mudaraba entre la entidad vehículo en calidad de inversor ( $r a b$ al-mal) y un gestor (mudareb), en virtud del cual la entidad vehículo constituye un fondo mediante la contribución de una aportación dineraria -con cargo a los fondos obtenidos de la suscripción de sukuk por los bonistas-, que es administrado por el gestor para la promoción de una determinada actividad económica. En la sukukal-musaraka la entidad vehículo acuerda con otros inversores la constitución de una comunidad de bienes o una sociedad mediante la contribución de aportaciones de capital -que la entidad vehículo realizará con cargo a los fondos obtenidos de la suscripción de sukuk por los bonistas-, que es administrada por todos o algunos de ellos o por un tercero designado al efecto para la promoción de una determinada actividad económica. Los expertos islámicos coinciden en señalar que la murabaha no es combinable con una emisión de sukuk dado que, una vez que un activo ha sido objeto de compraventa, cualquier negocio ulterior ligado a los beneficios que genere es incompatible con la sharía. En la práctica financiera se ha venido imponiendo la sukuk-al-iyara al otorgar a los bonistas una cuota de participación sobre un activo tangible o comunidad de bienes subyacente que es libremente transmisible y negociable en mercados secundarios -oficiales o no-, en tanto que las sukukal-mudaraba y sukuk-al-musaraka confieren al bonista un título representativo de una deuda -esto es, de una posición contractual acreedora que incorpora un interés crediticio contra un tercero-, que con arreglo a la sharía sólo es transmisible a la par -sin margen de beneficio- y en ningún caso susceptible de admisión a cotización en mercados secundarios oficiales.

${ }^{49}$ Con frecuencia, el contrato de murabaha viene acompañado de un contrato de mudaraba entre la entidad financiera y un fondo islámico, en virtud del cual el fondo islámico encomienda a la entidad financiera la inversión de invertir ciertos fondos con arreglo a la sharía. En la combinación de murabaha y mudaraba es habitual pactar que, una vez que el cliente ha instruido al proveedor para que entregue el activo a la entidad financiera, el fondo islámico, en el momento en que la entidad financiera adquiere el activo, transfiera el importe del precio de compraventa a la cuenta que el cliente haya abierto en la entidad financiera, desde la que el cliente a su vez realiza el pago al proveedor.

${ }^{50} \mathrm{Si}$ bien a veces se admite la figura de la posesión mediata, lo cierto es que, dependiendo de los prestamistas y del grado de cumplimiento con la sharía exigido por el banco estructurador, existen supuestos en los que dichos bancos desig- 
al «segundo contrato de compraventa», la entidad financiera vende el bien al cliente por un precio de " $\mathrm{x}+\mathrm{y}$ », que será abonado por el cliente de una sola vez en una determinada fecha o con arreglo a un calendario de pagos. La diferencia de precio que hemos denominado 'y' no refleja el coste financiero del cobro aplazado del precio por parte de la entidad financiera, sino el valor de mercado que el cliente y la entidad financiera han acordado asignarle al activo en una determinada fecha ${ }^{51}$. El cliente no está obligado a adquirir el activo, si bien, en la práctica la entidad financiera suele prevenir este riesgo mediante la obtención de un pagaré del cliente, una oferta irrevocable de compra y/o un pago anticipado del cliente ${ }^{52}$. La opción de compra combinada con un pago anticipado se denomina arbun y ha sido objeto de cierta controversia entre expertos islámicos ${ }^{53}$. Es habitual que la entidad financiera ceda al cliente las acciones que puedan corresponderle contra el proveedor bajo la cláusula de manifestaciones y garantías (representations and warranties). La murabaha es, en cierto modo, tributaria del contrato de crédito documentario, con la diferencia clave de que el banco deviene propietario de los bienes durante el periodo que media entre los dos contratos de compraventa y asume, al menos en teoría, los riesgos de pérdida o deterioro.

nan lugares físicos de su propiedad en los cuales se depositan los bienes objeto de la murabaha para demostrar la posesión inmediata del bien, no resultando suficiente la mediata. Véase CANALEJO LASARTE, G. / CABELLOS BALLENILLA, A. (2009), «Apuntes sobre los contratos «islámicos» de financiación desde la perspectiva del derecho español», Actualidad Jurídica Uría Menéndez, n. ${ }^{\circ} 23$, p. 32, nota al pie 56.

${ }^{51}$ En este caso «X» refleja el importe del precio de adquisición por el que la entidad financiera adquirió el activo del proveedor, incrementado en «y», que suele ser un margen vinculado al Libor o Euribor. El margen de beneficio que obtiene la entidad financiera se considera legítima dado que adquiere previamente el activo y con él el riesgo asociado a su propiedad antes de revenderlo al cliente.

${ }^{52}$ Un ejemplo para ilustrar el funcionamiento de la murabaha podría ser el siguiente: Un concesionario catarí contacta a un fabricante de automóviles con sede en Barcelona para adquirir una partida de automóviles. En lugar de adquirir directamente los automóviles, el concesionario designa a un banco de los Emiratos Árabes Unidos para que adquiera la partida de automóviles del fabricante. El banco designa al concesionario como agente para que negocie y formalice en su nombre la compraventa de la partida de automóviles con el fabricante. El banco paga el precio y adquiere la partida en el momento del embarque en el puerto de Barcelona, asumiendo todos los riesgos durante el trayecto hasta Catar. Una vez desembarcados en Catar, el banco vende al concesionario la partida por un precio que incluye un margen adicional con respecto al precio que pagó al fabricante.

${ }_{53}$ Algunos autores consideran que el reconocimiento de un derecho de opción de compra a favor del cliente contiene un elemento de garar (incertidumbre) posiblemente contrario a la sharía. Véase AL-ZAHAYLI, W. (2003), Financial Transactions in Islamic Jurisprudence, Dar Al-Fikr, pp. 99-100. 


\section{EL DERECHO ISLÁMICO COMO LEY APLICABLE}

Entre los principios básicos del derecho de contratación internacional está la autonomía de las partes a la hora de determinar la ley aplicable al contrato. Son ilustrativos a este respecto el artículo 3 del Reglamento 2008/593/CE, de 17 de junio, del Parlamento Europeo y del Consejo ( Reglamento Roma I») y el artículo 28(1) de la Ley Modelo de UNCITRAL sobre Arbitraje Comercial Internacional. En el ámbito de las finanzas islámicas existen fundamentalmente dos modelos de cláusulas, dependiendo de si las partes optan por someter el contrato exclusivamente a la sharía o, como suele ser más habitual, se decantan por un modelo mixto de sumisión al ordenamiento jurídico de un estado -generalmente el Reino Unido o el estado de Nueva York- y a la sharía. Teóricamente cabe una tercera opción -no demasiado frecuente en este contexto-, que sería la de someter el contrato exclusivamente a la ley de un determinado estado, si bien este caso no plantea especiales dificultades desde el punto de vista del conflicto de normas.

En el primer supuesto, esto es, si el contrato de financiación islámico queda sometido exclusivamente a la sharía, la determinación de la ley aplicable tampoco plantea muchos problemas en la actualidad, si bien es cierto que bajo el Convenio de Roma, antes de la entrada en vigor del Reglamento Roma I, la pregunta acerca de si el principio de autonomía de la voluntad de las partes comprendía la facultad de someter el contrato a un ordenamiento jurídico distinto del estatal fue objeto de cierta controversia ${ }^{54}$. En el contexto europeo, este debate fue especialmente notable a propósito de la sumisión de un contrato a la lex mercatoria, los Principios UNIDROIT de derecho internacional de los contratos (1994) así como los Principios de Derecho Contractual Europeo. La doctrina mayoritaria proponía soluciones distintas dependiendo de si el litigio se sustanciaba ante una corte de arbitraje o ante un tribunal estatal. En el caso del arbitraje, la validez de la cláusula de sumisión a un derecho no estatal -incluso a los principios de equidad- estaba ampliamente aceptada. Esta posición venía reforzada por el redactado del artículo 28(1) de la Ley Modelo de la CNUDMI sobre Arbitraje Comercial Internacional así como por numerosos estatutos de cortes de arbitraje internacional. El Reglamento Roma I no introduce ninguna novedad a este respecto, por lo que parece admisible la sumisión de un contrato a los principios de la

\footnotetext{
${ }^{54}$ En contra de esta posición, véase JUNIUS, A. (2007), «Islamic Finance: Issues surrounding Islamic Law as a Choice of Law under German Conflict of Laws Principles», Chicago Journal of International Law, vol. 7, no. 2, p. 546.
} 
sharía, siempre que la jurisdicción competente sea una corte de arbitraje cuyos estatutos reconozcan la elección de un derecho no estatal como ley aplicable al contrato ${ }^{55}$.

En el segundo supuesto, si la jurisdicción aplicable era un tribunal estatal, la cláusula de sumisión a la sharía no era válida conforme al Convenio de Roma. La posición doctrinal mayoritaria entendía que el tribunal estatal estaría vinculado por la interpretación de las normas de derecho internacional privado. En el contexto europeo, la interpretación tradicional del artículo 3(1) del Convenio de Roma insistía en que éste se refería exclusivamente a ordenamientos jurídicos estatales $^{56}$. Aunque el artículo 3(1) del Reglamento Roma I no difiere del artículo 3(1) del Convenio de Roma en este punto, el considerando (13) del Reglamento Roma I reconoce ahora que las partes pueden incorporar a su contrato por referencia un derecho no estatal o un convenio internacional. De ahí que la cláusula de sumisión a la sharía tampoco debiera ser válida conforme al Reglamento Roma I, si bien pudiera ser incorporada por referencia en tanto que derecho no estatal. Asimismo tampoco debiera plantear problemas el reconocimiento en los estados de la Unión Europea de una sentencia o laudo arbitral dictado en un tercer estado que reconozca alcance sustantivo y normativo propio a la sharía por virtud tanto del Reglamento (CE) 44/2001, de 22 de diciembre, del Consejo, sobre competencia judicial, reconocimiento y ejecución de sentencias como del Convenio sobre reconocimiento y ejecución de sentencias arbitrales hecho en Nueva York el 10 de junio de 1958.

Las cláusulas mixtas que contienen una doble remisión a la ley de un determinado estado y al derecho islámico son relativamente frecuentes. Un redactado habitual puede ser el siguiente: «con sujeción a los principios de la gloriosa sharía, este contrato se someterá y será interpretado conforme a las leyes de [Reino Unido / estado de Nueva York, etc.]» ${ }^{57}$. Sin perjuicio del supuesto de dépeçage descrito en el

${ }^{55}$ En el arbitraje comercial internacional no es del todo desconocida la remisión a ordenamientos jurídicos históricos, en particular, al derecho romano, que parece seguir gozando de una salud de hierro. Acerca del derecho romano como ley aplicable al contrato, véase KNÜTEL, R. (1994), «Rechtseinheit in Europa und römisches Recht», Zeitschrift für europäisches Privatrecht, pp. 244-276.

${ }^{56} \mathrm{Si}$ bien la elección de derecho no estatal podía ser válida en el plano sustantivo, véase «kollisionsrechtliche Verweisung vs. materiellrechtliche Verweisung» en KRO-

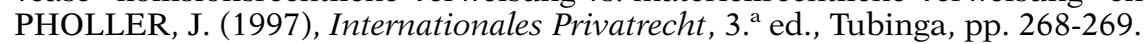

${ }^{57}$ Véase la clásula de sumisión del caso Shamil Bank of Bahrain EC v. Beximco Pharmaceuticals Ltd. citado supra: «Subject to the principles of the glorious Shari'a, this Agreement shall be governed by and construed in accordance with the laws of England». 
apartado siguiente, el artículo 3 del Reglamento Roma I establece claramente que las partes deben elegir «la» ley aplicable al contrato, de modo que no cabría someter el contrato a dos ordenamientos jurídicos distintos. De hecho, a pesar de que el redactado es ambiguo, la intención de las partes en la cláusula antes citada no es tanto la de someter el contrato a dos ordenamientos distintos, cuanto de elegir como «ley aplicable» el ordenamiento jurídico de una jurisdicción de reconocido prestigio en el tráfico financiero -cuyos órganos jurisdiccionales declinarán previsiblemente todo pronunciamiento en materia religiosa- e introducir una declaración programática de conformidad del contrato con la sharía. La sujeción a la sharía queda de esta manera reducida a la adhesión a unos principios éticos de inspiración islámica, cuyo cumplimiento es verificado ex ante -esto es, con anterioridad a la suscripción del contrato- por un experto islámico privado designado de común acuerdo entre las partes. Esta aproximación se ve habitualmente reforzada con la ya mencionada cláusula waiver of Shari'a defense. El deslinde entre ley secular y ley religiosa sería más difícil de operar si el contrato quedara sometido a las leyes de un estado que sí ha incorporado la sharía como fuente del derecho -por ejemplo Irán, Sudán, Paquistán o Arabia Saudí-. En estos supuestos parece poco probable que los órganos judiciales declinen su competencia en materia religiosa, de modo que cobraría virtualidad el denominado Shari'a risk, esto es, el riesgo de que un órgano judicial declare el derecho islámico como judiciable y emita pronunciamientos no previstos de antemano por las partes contratantes, además de potencialmente incompatibles con la práctica financiera convencional.

A pesar de la prohibición de someter un contrato a dos ordenamientos distintos, el artículo 3 del Reglamento de Roma I reconoce el supuesto de dépeçage, según el cual las partes pueden elegir la ley aplicable a la totalidad "o sólo a una parte del contrato», esto es, las partes pueden someter distintas partes del contrato a diferentes ordenamientos. La premisa necesaria en este supuesto es que el contrato sea claramente divisible «en partes». Si bien la murabaha presenta relaciones jurídicas claramente diferenciadas, las partes suelen optar por una cláusula de sumisión unitaria para todo el contrato, sea en sus modalidades simple o mixta antes mencionadas.

Una vez establecido que sólo cabe una ley aplicable al contrato con arreglo al Reglamento Roma I y que el supuesto de dépeçage no suele ser relevante en este contexto, cabe preguntarse acerca de la incorporación por referencia de la sharía-suponiendo que no medie una cláusula waiver of Shari'a defense-. Dentro de los límites de las 
leyes de policía referidos en el artículo 9 del Reglamento Roma I, la incorporación por referencia (materiellrechtlicher Verweis) tendría la virtualidad de derogar todas aquellas normas dispositivas del ordenamiento jurídico aplicable al contrato que fueran incompatibles con la sharía ${ }^{58}$. Comparado con el artículo 7 del Convenio de Roma, el artículo 9 del Reglamento Roma I reduce sensiblemente los supuestos de «leyes de policía» que permiten a un juez declarar inaplicable una norma de conflicto contenida en el reglamento. El artículo 9 diferencia entre las «consideraciones de interés público» y las disposiciones imperativas, distinción que no era del todo clara bajo el Convenio de Roma. El considerando (37) del Reglamento Roma I aclara que «el concepto de «leyes de policía» debe distinguirse de la expresión «disposiciones que no pueden excluirse mediante acuerdo» y debe interpretarse de manera más restrictiva». La noción de «leyes de policía» queda limitada a aquellas normas que salvaguarden ciertos intereses públicos, noción que no incluye normas sobre protección de partes contractuales -por ejemplo de derecho de consumidores-.

En el caso de la sharía, la incorporación por referencia presenta una complicación añadida y es que el órgano jurisdiccional competente inevitablemente se verá obligado a pedir un testimonio de los principios islámicos aplicables a los hechos. Como hemos visto, en materia de contratación bancaria, la sharía no representa una codificación de normas de contratación bancaria, sino más bien una relación de objetivos y principios, cuyo número y configuración exacta varía según las autoridades regulatorias y expertos islámicos consultados. Suponiendo que no medie una cláusula waiver of Shari'a defense y que las partes verdaderamente deseen incorporar ciertos preceptos islámicos al contrato por referencia, parece que la opción más prudente fuera delimitar con precisión en el contrato los principios relevantes. No parece que el catálogo de principios islámicos esenciales -prohibiciones de interés, especulación, incertidumbre e inversión en actividades prohibidas y mandatos de distribución del riesgo y de activos tangibles subyacentes-, sea necesariamente incompatible con las leyes de policía ni las disposiciones imperativas de los estados de la Unión Europea. Otra forma de proceder que se ha podido apreciar en los últimos años es la solicitud por las partes de una fetua a un experto islámico con el fin de que se pronuncie sobre la oportunidad de ejercitar o no ciertas pretensiones bajo el contrato con arreglo a la sharía.

${ }^{58}$ El caso más cercano sería la derogación de las normas en materia de intereses moratorios por incompatibilidad con la prohibición de riba. 
El caso Shamil Bank of Bahrain EC v. Beximco Pharmaceuticals $L t d$. representa, a día de hoy, el pronunciamiento más conocido de un tribunal inglés sobre un supuesto de cláusula mixta ${ }^{59}$. El tribunal desestima la pretensión de la demandante de que el contrato infringe ciertos preceptos de la sharía, considerando que, con arreglo al artículo 1 del Convenio de Roma, la ley aplicable al contrato debe ser única y necesariamente un ordenamiento jurídico estatal -en este caso el derecho inglés-. El tribunal aclara, además, que la sharía no reúne los requisitos de un ordenamiento jurídico estatal, entre otros motivos, por no estar suficientemente codificada, y no es susceptible de ser designada ley aplicable a un contrato. El tribunal confirma el razonamiento de la parte demandada de que la calificación religiosa del contrato no constituye materia judiciable dado que es anterior a la suscripción de éste y corresponde a un Shari'a Board su verificación. El tribunal no aborda la cuestión de la incorporación por referencia de la sharía -lógicamente, porque el caso se decide bajo la vigencia del Convenio de Roma y no existe una disposición equivalente al considerado (37) del Reglamento Roma I (vid. supra)- ni el supuesto de dépeçage, en vista de que no es disputado por las partes ${ }^{60}$.

${ }^{59}$ Shamil Bank of Bahrain EC v. Beximco Pharmaceuticals Ltd., $28^{\text {th }}$ January 2004, Arbitration, Practice \& Procedure Law Reports, CA on appeal from QBD (Morison J) before Potter LJ; Laws LJ; Arden LJ. Aunque menos significativo porque la referencia a la sharía estaba contenida en un expositivo y el tribunal evitó el pronunciamiento sobre la sharía en sede de ley aplicable, véase también Islamic Investment Company of the Gulf (Bahamas) Ltd. v. Symphony Gems N. V. \& Ors, 13 $3^{\text {th }}$ February 2002, 2001 Folio 1226 per Justice Tomlinson, 2002 West Law 346969, QBD (Comm Ct).

${ }^{60}$ Véase el resumen contenido en JUNIUS, A. (2007), "Islamic Finance: Issues surrounding Islamic Law as a Choice of Law under German Conflict of Laws Principles», Chicago Journal of International Law, vol. 7, no. 2, pp. 541-542: «The English Court, by upholding the decisión of the London High Court, explicitly rejected Beximco's argument. The English judges found that the agreement was subject solely to English law, and that a review for legality under Islamic law was not appropriate. The English Court emphasized at the outset that it would be non-justiciable, and therefore impossible for contracts, to be subject to two different legal systems since the relevant Rome Convention on the Law Applicable to Contractual Obligations states that "[a] contract shall be governed by the law chosen by the parties». This needs to be read in conjunction with Article 1 of the Rome Convention, according to which the Rules of the Convention «shall apply to contractual obligations in any situation involving a choice between the laws of different countries». This means that only the choice of a national legal system is a valid choice of law. The Rome Convention as a whole does not contemplate the choice of a non-state legal system such as Islamic law. In addition, the English Court characterized the principles of Shari'ah as representing a socio-religious code of conduct, something different from, and at the same time more and less than, a classic state legal system. Islamic law, in the view of the English Court, was also insufficiently determinate since it is debated even among its own legal scholars, and on the whole inadequately codified. The English Court further found it highly improbable that the parties to the contract would wish for a secular English court to decide a legal dispute on the basis of Islamic law. This reaso- 


\section{LEY APLICABLE A FALTA DE ELECCIÓN}

En el esquema de murabaha se pueden identificar tres relaciones jurídicas, como son (i) el contrato de comisión de compra entre el cliente y la entidad financiera; (ii) el contrato de compraventa que conciertan la entidad financiera y el proveedor del activo; y (iii) el contrato de compraventa que conciertan el cliente y la entidad financiera. Conviene señalar, en primer lugar, que el contrato de comisión de compra así como el contrato de compraventa entre el cliente y la entidad financiera no suelen plantear problemas de conflicto de normas bajo el Reglamento Roma I dado que las partes generalmente tendrán su domicilio social en la misma jurisdicción, por lo que rara vez nos encontraremos ante un contrato internacional en el sentido del artículo 1.1 del Reglamento de Roma I. Sin embargo, desde el punto de vista del conflicto de normas, merecen un examen más detallado dos cuestiones relativas al contrato de compraventa que conciertan la entidad financiera y el proveedor del activo; de un lado, la obligación de la entidad financiera de pagar el precio al proveedor -pensemos en el supuesto de que la entidad financiera declina el pago del precio, por el motivo que sea- $y$, de otro, las acciones que asisten a la entidad financiera (o al cliente, en caso de cesión de las pretensiones bajo la cláusula de manifestaciones y garantías) contra el proveedor en caso de entrega de un activo defectuoso.

En defecto de elección o de cláusula válida de ley aplicable, dispone el artículo 4(2) del Reglamento Roma I que el contrato se regirá

ning by the English Court upheld the lower court's observation that there was no compelling interest to examine religious questions, since the Shari'ah boards of the relevant parties had already done so and passed their judgment. Both the English Court and the London High Court thus reached the result that the contractual reference to Islamic law was nothing more than a non-binding statement of purpose by the bank to pursue Shari'ah compliant financing. The English Court concluded with the self-confident assertion that English law, distinguished internationally for its popularity and high quality, should not be diluted by religious principles. In doing so, the English court rejected the defense by noting that the commercial reality of the agreement was clear to both parties from the beginning, and this reality must be considered in interpreting the agreement. A loan transaction was hidden in murabaha clothing.

The English Court made it unmistakably clear that it would generally uphold agreements in which religious Islamic parties are participants so long as the agreements can be reconciled with English law. Furthermore, English courts will not take the place of the Shari'ah boards by reviewing a contract's consistency with Islamic law. The judgment takes care to secure substantial legal certainty for financial institutions. It thus shifts and reduces the particularities of Islamic finance to the preparation of the contract and the internal review of the relevant materials. This ultimately makes dependable legal advice necessary». 
por la ley del país donde tenga su residencia habitual la parte que deba realizar la prestación característica del contrato. En el caso de la murabaha no resulta sencillo determinar la prestación característica del contrato, dado que nos encontramos ante tres relaciones jurídicas distintas ligadas por una función económica común como es la financiación a través de un préstamo o crédito, generalmente de corto o medio plazo. Bajo el artículo 4(2) del Reglamento Roma I se plantean dos cuestiones estrechamente conectadas: (i) de un lado, si el esquema de murabaha en su conjunto debe quedar sometido a una única ley aplicable o si, por el contrario, las relaciones jurídicas que lo integran pueden quedar sometidas a distintas leyes aplicables; y (ii) si la prestación característica del contrato debe ser definida atendiendo a la entrega del activo que es objeto de los dos contratos de compraventa o bien atendiendo a la función económica de financiación a la que obedece la murabaha en su conjunto ${ }^{61}$.

En relación con la primera cuestión, en el caso de la sumisión unitaria a una sola ley aplicable, el resultado puede ser distinto dependiendo si se consideran como prestación característica del contrato la concesión de la financiación o las entregas del activo bajo los dos contratos de compraventa. En el primer caso, la ley aplicable sería la de la jurisdicción en la que la entidad financiera tenga su domicilio social. En el segundo caso, si la prestación característica del contrato fueran las entregas del activo, parece que no cabría más opción que separar las dos relaciones jurídicas de compraventa, siendo aplicable la Convención de las Naciones Unidas sobre los Contratos de Compraventa Internacional de Mercaderías («Convención de Viena») o la ley de la jurisdicción del vendedor, según los casos.

En relación con la segunda cuestión, la sumisión de diferentes partes de la murabaha a distintas leyes aplicables parecería, a priori, más acorde a su naturaleza, en la medida que incorpora elementos tanto de una adquisición de activo como de una financiación, pero lo cierto es que no encaja bien ni en la simple compraventa ni en el mero contrato de préstamo o crédito. Esta naturaleza dual parece que debiera encontrar reflejo bajo el régimen de normas de conflicto, separando las potenciales disputas relacionadas con los componentes

${ }^{61}$ A propósito de la pregunta de si en una operación compleja, compuesta de una pluralidad de relaciones jurídicas, debe identificarse un único contrato mayor sobre la base del cual se determine la ley aplicable al contrato; o bien admitir la noción de dépeçage en virtud de la cual la operación se desglosaría en varias partes componentes, potencialmente sometidas a diferentes leyes aplicables, véase BÄLZ, K., «Islamic Law as Governing Law under the Rome Convention. Universalist Lex Mercatoria vs. Regional Unification of Law», op. cit., p. 46. 
de «adquisición» y de «financiación» de la murabaha. El artículo 4(1) in fine del Convenio de Roma admitía de forma excepcional la noción de dépeçage al disponer que «[...]. No obstante, si una parte del contrato fuera separable del resto del contrato y tuviese una conexión más estrecha con otro país, podrá aplicarse, a título excepcional, a esta parte del contrato la ley de este otro país». Bajo el Reglamento de Roma I la situación es un poco más ambigua. Aunque el artículo 3(1) del Reglamento de Roma I admite la posibilidad de que las partes sometan el contrato a distintas leyes aplicables, el artículo 4 elimina toda referencia a la pluralidad de leyes aplicables a un contrato a falta de elección de las partes. La separación de leyes aplicables a la murabaha tendría la virtualidad de ofrecer remedios jurídicos diferenciados en los dos escenarios de disputa que son relevantes desde el punto de vista del conflicto de normas. De un lado, en una disputa entre el proveedor y la entidad financiera -pensemos, por ejemplo, en el supuesto de que la entidad financiera se niegue a pagar el precio-, la murabaha podría ser calificada como contrato de crédito documentario, siendo la ley aplicable la de la jurisdicción del domicilio social de la entidad financiera, que determinaría la obligación de la entidad financiera de abonar el precio en el caso de que se hayan presentado válidamente los documentos que justifican la reclamación ${ }^{62}$. De otra parte, en una disputa entre el proveedor y el cliente -pensemos en una reclamación por vicios de la cosa entregada y recordemos que habitualmente la entidad financiera cede al cliente las pretensiones que puedan corresponderle contra el proveedor bajo la cláusula de manifestaciones y garantías del "primer contrato de compraventa»-, la murabaha podría ser calificada de contrato de compraventa sujeta a la Convención de Viena ${ }^{63}$ o a la ley de la jurisdicción en la que el proveedor tenga su residencia habitual con arreglo al artículo 4(1) a) del Reglamento Roma I, basando el cliente su reclamación en el artículo 14(2) del Reglamento Roma I, que dispone que la ley que rija el crédito objeto de cesión o subrogación «determinará las relaciones entre el cesionario o subrogado y el deudor».

\section{CONCLUSIONES}

El derecho financiero islámico se puede definir como un cuerpo de principios de contratación bancaria -no siempre positivados en un ordenamiento jurídico estatal- coherente con los preceptos del Islam.

\footnotetext{
${ }^{62}$ Véase el artículo 22 de la Convención de las Naciones Unidas sobre Garantías Independientes y Cartas de Crédito Contingente.

${ }^{63}$ Suponiendo que se cumplan los requisitos de los artículos 1 a 6.
} 
De acuerdo con la visión tradicional, el derecho financiero islámico forma parte del derecho positivo de un determinado estado y su creación se enmarca dentro de un proceso más amplio de «islamización» del ordenamiento jurídico secular. Aunque este es el caso de algunos países, la visión tradicional del derecho financiero islámico no acierta a describir un segundo fenómeno surgido de la moderna práctica financiera y que podríamos denominar con cierta cautela «responsabilidad corporativa islámica». La noción de derecho financiero islámico entendido en este último sentido describe un compendio de buenas prácticas islámicas de adhesión voluntaria en materia de contratación bancaria, creadas y aplicadas al margen de los ordenamientos jurídicos seculares inspirados o no por la sharía.

En el ámbito de las finanzas islámicas y, en particular, del esquema denominado murabaha, existen fundamentalmente dos modelos de cláusulas, dependiendo de si las partes optan por someter el contrato exclusivamente a la sharía o, como suele ser más habitual, se decantan por un modelo mixto de sumisión al ordenamiento jurídico de un estado -generalmente el Reino Unido o el estado de Nueva York- y a la sharía. En el primer supuesto la determinación de la ley aplicable no plantea muchos problemas. En el caso del arbitraje, el Reglamento Roma I parece admitir la sumisión de un contrato a los principios de la sharía, siempre que la jurisdicción competente sea una corte de arbitraje cuyos estatutos reconozcan la elección de un derecho no estatal como ley aplicable al contrato. En el caso de que la jurisdicción aplicable sea un tribunal estatal, la lectura conjunta del artículo 3(1) y del considerando (13) del Reglamento Roma I sugiere que las partes pueden incorporar a su contrato por referencia un derecho no estatal o un convenio internacional.

El caso de las cláusulas mixtas que contienen una doble remisión a la ley de un determinado estado y al derecho islámico es, prima facie, problemático dado que el artículo 3 del Reglamento Roma I dispone que las partes deben elegir «la» ley aplicable al contrato, de modo que no cabría someter el contrato a dos ordenamientos jurídicos distintos. No obstante, esta posición no contradice la intención habitual de las partes, que no buscan tanto someter el contrato a dos ordenamientos distintos, cuanto elegir como «ley aplicable» el ordenamiento jurídico de una jurisdicción de reconocido prestigio en el tráfico financiero -cuyos órganos jurisdiccionales declinarán previsiblemente todo pronunciamiento en materia religiosa- e introducir una declaración programática de conformidad del contrato con la sharía. 
A pesar de que el reconocimiento de la sharía como ley aplicable al contrato parece factible bajo el Reglamento Roma I en algunos casos -especialmente cuando la jurisdicción aplicable es una corte arbitral-, el denominado Shari'a risk -esto es, el riesgo de que un órgano jurisdiccional secular decida pronunciarse sobre cuestiones religiosas y, eventualmente, realice una interpretación distinta a la esperada en la práctica de mercado convencional-, lleva a los operadores a relegar la evaluación de conformidad con la sharía a una fase precontractual. El Shari'a risk resulta aún más acuciante si el contrato queda sometido a las leyes de un estado que ha incorporado la sharía como fuente del derecho de su ordenamiento jurídico. No resulta sorprendente que sea precisamente en estas jurisdicciones donde el derecho financiero islámico entendido como 'responsabilidad corporativa islámica' goce de menor implantación y, sin embargo, prospere en jurisdicciones con una clara separación de religión y estado. Con el fin de prevenir el riesgo de «judicialización» del derecho financiero islámico es cada vez más habitual que las partes contratantes estipulen una cláusula denominada "waiver of Sharía defense», esto es, una renuncia de las partes a invocar la falta de conformidad del contrato con los preceptos islámicos. En línea con esta idea, el derecho financiero islámico es percibido más como un «riesgo» para el éxito de una operación de financiación que como una "norma», cuya función primordial debiera ser precisamente la de dar seguridad a la operación. Frente a este riesgo, la emisión de dictámenes por agencias privadas genera seguridad jurídica en el tráfico -entendida como congruencia con la sharía de un esquema de financiación cuyo contenido económico responde, en el fondo, a la práctica financiera convencional-, con la ventaja añadida de que la obtención del dictamen facilita la inclusión de la cláusula «waiver of Shari'a defense» en el contrato, eliminando de antemano, o al menos en teoría, el riesgo de judicialización de las cuestiones religiosas.

La sentencia del tribunal inglés en el caso Shamil Bank of Bahrain EC v. Beximco Pharmaceuticals Ltd., decidido bajo la vigencia del Convenio de Roma, vino a confirmar que, en el supuesto de cláusulas mixtas, la ley aplicable al contrato debe ser única y necesariamente un ordenamiento jurídico estatal -en aquel caso, el derecho inglés-. El tribunal aclaró, además, que la sharía no reúne los requisitos de un ordenamiento jurídico estatal, entre otros motivos, por no estar suficientemente codificada, y no es susceptible de ser designada ley aplicable a un contrato. El tribunal consideró que la calificación religiosa del contrato no constituye materia judiciable dado que es anterior a la suscripción de éste y corresponde a un Shari'a Board su ve- 
rificación. En su momento, la sentencia fue aplaudida por algunas entidades financieras islámicas precisamente porque confirmaba una cierta concepción de las finanzas islámicas y en la medida en que contribuía a generar seguridad jurídica en este sector de mercado. Sin embargo, la sentencia no aborda la cuestión de la incorporación por referencia de la sharía -recordemos que el caso se decide bajo la vigencia del Convenio de Roma y no existe una disposición equivalente al considerado (37) del Reglamento Roma I (vid. supra)- ni el supuesto de dépeçage, en vista de que no fue disputado por las partes. De ahí que no pueda descartarse que un tribunal europeo decida, en un futuro, evaluar la compatibilidad de un contrato de financiación islámico con la sharía. 